\title{
Calculation CoOling Compressors
}

\author{
Halima Hadziahmetovic
}
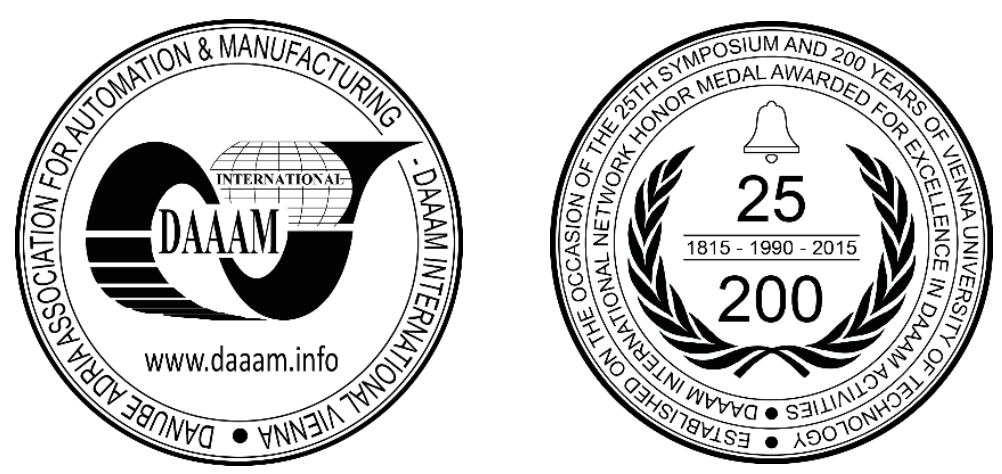

This Publication has to be referred as: Hadziahmetovic, H[alima] (2016). Calculation Cooling Compressors, Proceedings of the 27th DAAAM International Symposium, pp.0203-0212, B. Katalinic (Ed.), Published by DAAAM International, ISBN 978-3-902734-08-2, ISSN 1726-9679, Vienna, Austria

DOI: $10.2507 / 27$ th.daaam.proceedings.030

\begin{abstract}
In many systems of compressed air, besides the proper selection of the compressor, there are significant opportunities to save energy, including energy recovery, pressure reduction, reducing leakage losses and optimization of systems and control systems. When planning investments in the construction of the compressed air system, it is necessary to examine and evaluate them. In addition, importance must be given to possible future requirements that the system must meet, as well as all other possible influences on the compressed air system. Typical examples of the mentioned influences are the environmental conditions requirements, requirements for energy savings, and increased quality requirements in production and possible future investment in the growth of production. In this paper is explained calculation cooling compressors. Cooling of compressors is going to be done in two cycles. In first cycle technological water circulates by pumps of first cycle. In second cycle "demi" water will circulate and cooled compressors and coolers of compressed air and also will be drived by pumps.
\end{abstract}

Keywords: pneumatic conveying; cooling; compressor; compressed air.

\section{Introduction}

Recently, much attention is paid to preserving the environment, and build systems that prevent pollution of the environment. Thermal power plants are one of the biggest environmental polluters. In the process of electricity production as coal combustion products occur large amounts of waste material. Transportation and disposal of fly ash and bottom ash are among the vital technological systems of each power plant that burns coal. The system of transport of fly ash and bottom ash in the thermal power plant can be: transportation by belt conveyors, transportation with dumper-trucks, hydraulic transport and pneumatic conveying [5,9].

The pneumatic transport involves the transportation powder, granular and piece of material and is based on the phenomenon that at the appropriate velocity of air in the pipeline, the solid particles are brought in the desired direction. Selection and efficiency of pneumatic transport depends of physical and chemical characteristic of the fly ash [2,11].

Compressors are mechanical devices used for raising the pressure of gas or vapour either by lowering its volume (as in the case of positive displacement machines) or by imparting to it a high kinetic energy which is converted into pressure in a diffuser (as in the case of centrifugal machines). The selection of compressors for different applications is a crucial 
issue in the process industry. It is usually the most expensive piece of equipment and has dominant influence on cycle efficiency. The common types of compressors used in industry are reciprocating, twin screw, single screw, centrifugal, scroll and rotary vane. In this paper is explained calculation cooling compressors. For properly system sizing ability, it is important to know the system function condition, pipe network, equipment position, and conveying medium characteristics (in this case compressed air) $[3,6,10]$.

In this paper is presented a system of preparation and distribution of compressed instrument air to the consumer in the system of internal pneumatic transport of fly ash under the electrofilter, flues and steam air heaters and calculation cooling compressors. System of compressed air for electrofilter is an integral part of a whole, the pneumatic transport of fly ash for the silo. The quantity of fly ash shown in table 1 and list of design input data are shown in tables 2 and 3.

\begin{tabular}{|c|c|}
\hline Input data & Value \\
\hline Fly ash: & $165-232,2 \mathrm{t} / \mathrm{h}$ \\
\hline $\begin{array}{c}\text { Ash from boiler hoppers and air preheater hopper: } \\
\text { (this ash is included in the sum for fly ash) }\end{array}$ & $14,0-17,8 \mathrm{t} / \mathrm{h}$ \\
\hline
\end{tabular}

Table 1 . The quantity of ash produced by one unit

\begin{tabular}{|c|c|}
\hline Input data & Value \\
\hline Bulk density of fly ash & $0,74 \mathrm{t} / \mathrm{m}^{3}$ \\
\hline Specific mass density & $2,22 \mathrm{~g} / \mathrm{cm}^{3}$ \\
\hline
\end{tabular}

Table 2. Design data

\begin{tabular}{|c|c|}
\hline Input data & Value \\
\hline Long distance fly ash pneumatic conveying & $\begin{array}{c}260 \mathrm{t} / \mathrm{h} \text { per unit (including15\% } \\
\text { reserve) }\end{array}$ \\
\hline
\end{tabular}

Table 3. Capacity data of the system

\section{Technical description}

\subsection{Compressed air distribution}

Compressed air is distributed by seamless steel galvanized pipelines. Distribution pipeline is oriented towards consumers, apropos to all valves on pneumatic drive which are located under electrofilter (EPS) of unit 1 and unit 2, and to the consumers in pump stations 1 and 2. In function of assigned pressure, complete pipeline is dimensioned, apropos diameters of certain sections are specified.

\subsection{Compressed air consumers}

Compressed air is used for manipulation and control in pneumatic transport process as well as for manipulation of pneumatic valves which are within automatic control of pneumatic transport. Locations which are supplied with compressed air: pressure vessels for pneumatic fly ash transport, air transport pipeline, armatures of ash receiver (plate gate valves), ash transport pipelines and pneumatic valves in bager station. Consumers, apropos places which are needed to be supplied with compressed air, altogether there are 226 pieces. Function of these valves is in program control of fly ash transport process which is managed by PLC. Safe operation of installation, apropos maintaining pressure in installation within limitations of minimal and maximal permissible pressure is supplied with regulation system which is located in the compressor. Compressor is in mutual automatic operation with reservoir of instrumental air where pressure should be between 6,3 - 7,5 bars. When pressure in reservoir drops under 7,5 bars, and reaches value of minimum permissible operation pressure $\mathrm{p}_{\min }=6,3 \mathrm{bars}$, automatically one compressor activates until maximal wanted pressure is not reached [4].

\section{Selection of compressor for compressed air under electrofilter}

- Air consumption by consumer for transmition in block 1: $\mathrm{Q}_{1}=53 \mathrm{~m}^{3} / \mathrm{h}$.

- Air consumption by consumer for transmition in block 2: $\mathrm{Q}_{2}=53 \mathrm{~m}^{3} / \mathrm{h}$.

- Air consumption by consumer for transmition in pump stations 1 and 2 like consumers on air preheaters and under channel of flue gases: $\mathrm{Q}_{3}=15 \mathrm{~m}^{3} / \mathrm{h}$.

- Total air consumption increased for $20 \%: \mathrm{Q}=1,2 \cdot\left(\mathrm{Q}_{1}+\mathrm{Q}_{2}+\mathrm{Q}_{3}\right)=1,2 \cdot 121=145,2 \mathrm{~m}^{3} / \mathrm{h}$. 
On the basis of calculated consumption of $145,2 \mathrm{~m}^{3} / \mathrm{h}$ compressor of firm Atlas Copco is selected:

Type: GA15+, Capacity: $160 \mathrm{~m}^{3} / \mathrm{h}$, Operation pressure: 7,5 bara , Power of electromotor: $15 \mathrm{~kW}$, Noise level: $64 \mathrm{~dB}$, Dimensions 1400 x 1225 x $650[1,4]$.

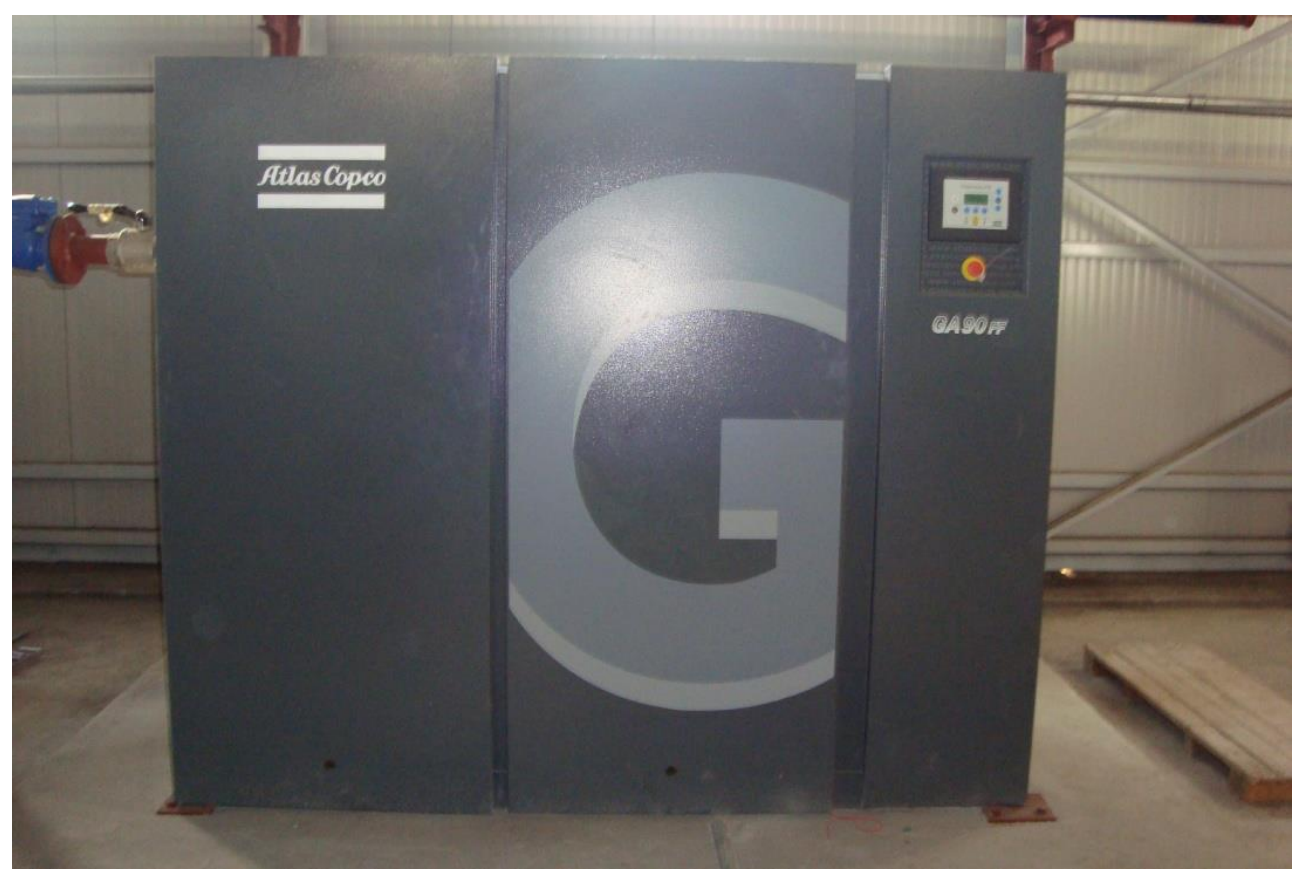

Fig 1. Compressor

On the base of selected compressor and according to Atlas Copco recommendation absorption dryers type CD 44 (2 piece) are chosen (Fig. 1). And on the base of experience in designing system of compressed air, instrumental air reservoir is selected, volume $\mathrm{V}=2 \mathrm{~m}^{3}$.

\section{Calculation cooling compressors}

Compressors (Fig. 2) of compressed air are water cooled, while compressors of control air are air cooled. Water for cooling of compressed air and compressors is used in secondary circuit which is closed. A water tank will be used to supply additional water should any losses of water occur during circulation. Water from primary circuit is supplied from unit 1 and flows to bager station. Circulation pump, heat exchanger and pipeline were selected in accordance with calculation.

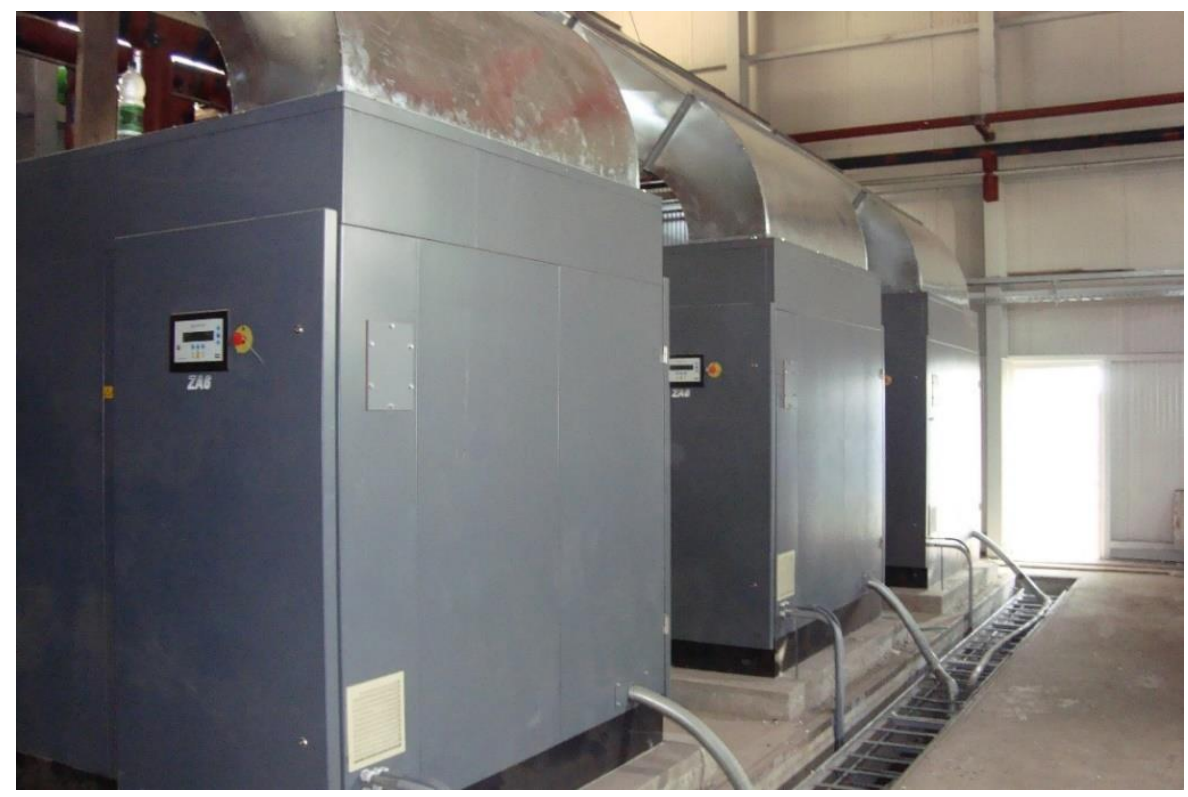

Fig 2. Compressors 


\subsection{Calculation of quantity of water for cooling of compressor and compressed air of secondary circuit}

Calculation of quantity of water for cooling of compressor and compressed air of secondary circuit be calculated according to the following:

$$
Q_{u k}=5 Q_{k 1}+2 Q_{k 2}
$$

where $Q_{K 1}=11,5 l / s=41,4 m^{3} / h$ is quantity of water for cooling of compressor and compressed air $\left(Q=5600 \mathrm{~m}^{3} / \mathrm{h}\right)$ and $Q_{K 2}=4,66 l / s=16,7 \mathrm{~m}^{3} / \mathrm{h}$ is quantity of water for cooling of compressor and compressed air $\left(Q=940 \mathrm{~m}^{3} / \mathrm{h}\right)$.

$$
Q_{u k}=5 \cdot 41,4+2 \cdot 16,7=240 m^{3} / h
$$

Reserve of water for one compressor is applied in above $\left(\mathrm{Q}=5600 \mathrm{~m}^{3} / \mathrm{h}\right)$.

\subsubsection{Determining dimensions of secondary circuit pipeline of cooling water}

Determining dimensions of secondary circuit pipeline of cooling water is given by:

$$
d=\sqrt{\frac{4 \cdot Q_{u k}}{\pi \cdot v}},
$$

where $\mathrm{v}=2 \mathrm{~m} / \mathrm{s}$ is assumed water velocity in cooling pipeline.

$$
d=\sqrt{\frac{4 \cdot 240}{\pi \cdot 2 \cdot 3600}}=206 \mathrm{~mm}
$$

Nominal diameter DN $200(\varnothing 219,1$ X 5,9) is selected.

\subsubsection{Calculation of actual water velocity in pipeline}

Actual water velocity in pipeline be calculated according to the following:

$$
v=\frac{4 \cdot Q_{u k}}{\pi \cdot d_{p}^{2}}=1,97 m / s
$$

where is $d_{p}=219,1-2 \times 5,9=207,3 \mathrm{~mm}=0,2073 \mathrm{~m}$.

Water velocity in cooling pipeline:

$$
v=\frac{4 \cdot 240}{\pi \cdot 0,2073^{2} 3600}=1,976 \mathrm{~m} / \mathrm{s} .
$$

\subsubsection{Pipeline features and local losses}

Length of pipeline is $\mathrm{L}=60 \mathrm{~m}$. List of pipeline features and local losses is shown in table 4 .

\begin{tabular}{|c|c|}
\hline Pipeline features & Local losses \\
\hline 10 elbows $90^{\circ} \mathrm{R}=3 \mathrm{D}$ & $10 * 0,5=5$ \\
\hline 10 elbows $45^{\circ} \mathrm{R}=3 \mathrm{D}$ & $10 * 0,5=5$ \\
\hline 20 valves & $20 * 0,6=12$ \\
\hline $6 \mathrm{~T}$ - pieces & $6 * 0,6=3,6$ \\
\hline & $\Sigma \xi=25,6$ \\
\hline
\end{tabular}

Table 4. Pipeline features and local losses

\subsubsection{Calculation of pressure drop in secondary cooling circuit}

Pressure drop in secondary cooling circuit can be determined by: 
$\Delta p_{u}=\Delta p+\Delta p_{k}+\Delta p_{i}$,

where $\Delta p=\Delta p_{1}+\Delta p_{2}$ is pressure drop in pipeline ( $\Delta p_{1}$ - pressure drop in straight pipe and $\Delta p_{2}$ - pressure drop due to local losses), $\Delta p_{k}=0,55$ bar is pressure drop through compressors and $\Delta p_{i}=0,45$ bar is pressure drop through heat exchanger.

Pressure drop in straight pipe should be calculated according to the following:

$$
\Delta p_{1}=\lambda \frac{L}{d_{p}} \cdot \frac{v^{2}}{2 g}
$$

where $\lambda=0,0144+0,00947 / \sqrt{v}=0,0211$ is coefficient of air friction using Weissbach method.

$$
\Delta p_{1}=0,12 b a r .
$$

Pressure drop due to local losses should be calculated according to the following:

$$
\Delta p_{2}=\frac{v^{2}}{2 g} \cdot \xi
$$

where $\xi=25,6$ is local losses and pressure drop in pipeline is given by:

$$
\Delta p_{2}=0,528 b a r
$$

and pressure drop in pipeline

$$
\Delta p=0,12+0,528=0,648 \text { bar. }
$$

Pressure drop in secondary cooling circuit can be determined by (4):

$$
\Delta p_{u}=0,648+0,55+0,45=1,65 \text { bar } .
$$

\subsubsection{Selection of circulation pump in secondary circuit}

Pump power is given by:

$$
N=\frac{Q_{u k} \cdot H_{p} \cdot \rho \cdot g}{367 \cdot \eta},
$$

where $\rho=1000 \mathrm{~kg} / \mathrm{m}^{3}$ is water density in secondary circulit, $\eta=0,7$ is coefficient of device usage, $Q_{u k}$ - total water flow in secondary circuit and $H_{p}$ - pump head.

Total water flow in secondary circuit can be determined by (1):

$$
Q_{u k}=5 \cdot 41,4+2 \cdot 16,7=240 m^{3} / h,
$$

where $Q_{K 1}=11,5 l / \mathrm{s}=41,4 \mathrm{~m}^{3} / \mathrm{h}$ is quantity of water for cooling of compressor and compressed air $\left(Q=5600 \mathrm{~m}^{3} / \mathrm{h}\right)$ and $Q_{K 2}=4,66 l / s=16,7 \mathrm{~m}^{3} / \mathrm{h}$ is quantity of water for cooling of compressor and compressed air $\left(Q=940 \mathrm{~m}^{3} / \mathrm{h}\right)$.

Pump head should be calculated according to the following:

$$
H_{p}=\Delta p_{i}+\Delta p_{k}+\Delta p,
$$

where $\Delta p_{i}=0,45 \mathrm{bar}$ is pressure drop in heat excanger, $\Delta p_{k}=0,55 \mathrm{bar}$ is pressure drop in compressor and $\Delta p=0,65 b a r$ pressure drop local losses.

$$
H_{p}=0,45+0,55+0,65=1,65 b a r
$$

Pump power can be determined by (7): 


$$
\begin{aligned}
& N=\frac{240 \cdot 1,65 \cdot 1 \cdot 9,81}{367 \cdot 0,7}=15,1 \mathrm{~kW} . \\
& N_{m}=\frac{N}{\mu},
\end{aligned}
$$

where $\mu=0,9$ is coefficient of device safety,

$$
N_{m}=16,8 \mathrm{~kW}
$$

Standard pump motor with $N=18,5 \mathrm{~kW}$ will be used.

The characteristics of the pump:

Firm: WILO, Type: IL150/260-18,5/4, Flow range: 216 m³/h, Motor power: 18,5 kW and Weight $309 \mathrm{~kg}$ [7].

\subsection{Selection of circulation pump in primary circuit}

Total water flow in primary circuit can be determined by:

$$
\dot{m}_{t \dot{v}}=\frac{i_{2}^{u l}-i_{2}^{i z}}{i_{1}^{i z}-i_{1}^{l l}} \cdot \dot{m}_{d v},
$$

where are:

$\dot{m}_{d v}=60,02 \mathrm{l} / \mathrm{s}=216 \mathrm{~m}^{3} / \mathrm{h}$ - total water flow in secondary circuit,

$i_{2}^{u l}=209,34 \mathrm{~kJ} / \mathrm{kg} \quad\left(t=50^{\circ} \mathrm{C}\right)$ - enthalpy secundary circulit water at outlet heat excanger,

$i_{2}^{i z}=167,53 \mathrm{~kJ} / \mathrm{kg} \quad\left(t=40^{\circ} \mathrm{C}\right)$ - enthalpy secondary circulit water at outlet heat excanger,

$i_{1}^{u l}=117,37 \mathrm{~kJ} / \mathrm{kg} \quad\left(t=28^{\circ} \mathrm{C}, p=3,5 \mathrm{bar}\right)$ - enthalpy primary circulit water at inlet heat excanger,

$i_{1}^{i z}=142,25 \mathrm{~kJ} / \mathrm{kg} \quad\left(t=35^{\circ} \mathrm{C}, p=3,5 \mathrm{bar}\right)$ - enthalpy primary circulit water at outlet heat excanger.

$$
\dot{m}_{t \dot{v}}=\frac{209,34-167,53}{142,25-117,37} \cdot 60,02=100 l / s=360 m^{3} / h
$$

\subsubsection{Determining dimensions of primary circuit pipeline of cooling water}

Determining dimensions of primary circuit pipeline of cooling water is given by:

$$
d=\sqrt{\frac{4 \cdot \dot{m}_{t v}}{\pi \cdot v}}
$$

where $v=2 \mathrm{~m} / \mathrm{s}$ is assumed water velocity in cooling pipeline.

$$
d=\sqrt{\frac{4 \cdot 360}{\pi \cdot 2 \cdot 3600}}=252,3 \mathrm{~mm}
$$

Nominal diameter DN $250(\varnothing 273$ X 6,3) is selected.

\subsubsection{Calculation of actual water velocity in pipeline}

Actual water velocity in pipeline be calculated according to the following:

$$
v=\frac{4 \cdot \dot{m}_{t v}}{\pi \cdot d_{p}^{2}},
$$

where is $d_{p}=273-2 \times 6,3=260,4 \mathrm{~mm}=0,2604 \mathrm{~m}$. 


$$
v=\frac{4 \cdot 360}{\pi \cdot 0,2604^{2} \cdot 3600}=1,88 \mathrm{~m} / \mathrm{s}
$$

\subsubsection{Pipeline features and local losses}

Length of pipeline is $\mathrm{L}=700 \mathrm{~m}$. List of pipeline features and local losses is shown in table 5 .

\begin{tabular}{|c|c|}
\hline Pipeline features & Local losses \\
\hline 15 elbows $90^{\circ} \mathrm{R}=3 \mathrm{D}$ & $15^{*} 0,5=7,5$ \\
\hline 2 elbows $45^{\circ} \mathrm{R}=3 \mathrm{D}$ & $2 * 0,5=1$ \\
\hline 2 elbows $30^{\circ} \mathrm{R}=3 \mathrm{D}$ & $2 * 0,5=1$ \\
\hline 6 valves & $6^{*} 0,6=3,6$ \\
\hline 6 T- pieces & $6^{*} 0,6=3,6$ \\
\hline & $\Sigma \xi=16,7$ \\
\hline
\end{tabular}

Table 5. Pipeline features and local losses

\subsubsection{Calculation of pressure drop in primary cooling circuit}

Pressure drop in straight pipe should be calculated according to the following (5):

$$
\Delta p_{1}=1,02 b a r
$$

where $\lambda=0,0144+0,00947 / \sqrt{v}=0,0211$ is coefficient of air friction using Weissbach method.

Pressure drop due to local losses should be calculated according to the following (6):

$$
\Delta p_{2}=0,3 b a r
$$

where $\xi=16,7$ is local losses and pressure drop in pipeline should be calculated according to the following:

$$
\Delta p=1,02+0,3=1,32 \text { bar } .
$$

Pressure drop in secondary cooling circuit can be determined by (4):

$$
\Delta p_{u}=1,32+0,55+0,45=2,32 \text { bar, }
$$

where $\Delta p_{k}=0,55 \mathrm{bar}$ is pressure drop through compressors and $\Delta p_{i}=0,45 \mathrm{bar}$ is pressure drop through heat exchanger.

\subsubsection{Selection of circulation pump in primary circuit}

Pump power is given by:

$$
N=\frac{\dot{m}_{t v} \cdot H_{p} \cdot \rho \cdot g}{367 \cdot \eta}
$$

where $\rho=1000 \mathrm{~kg} / \mathrm{m}^{3}$ is water density in secondary circuit, $\eta=0,7$ is coefficient of device usage, $H_{p}$-pump head and $\dot{m}_{t \dot{v}}$ - total water flow in primary circuit $\left(99 l / \mathrm{s}=360 \mathrm{~m}^{3} / \mathrm{h}\right)$.

Pump head should be calculated according to the following (8):

$$
H_{p}=0,45+0,55+1,32=2,32 \text { bar },
$$

where $\Delta p_{i}=0,45 \mathrm{bar}$ is pressure drop in heat exchanger, $\Delta p_{k}=0,55 \mathrm{bar}$ is pressure drop in compressor and $\Delta p=1,32 \mathrm{bar}$ pressure drop local losses.

Pump power can be determined by (13): 


$$
N=\frac{360 \cdot 2,32 \cdot 1 \cdot 9,81}{367 \cdot 0,7}=31 \mathrm{~kW}
$$

and

$$
N_{m}=\frac{31}{0,9}=35 \mathrm{~kW},
$$

where $\mu=0,9$ is coefficient of device safety.

Standard pump motor with $N=45 \mathrm{~kW}$ will be used.

The characteristics of the pump: Firm: WILO, Type: IL200/320-45/4, Flow range: $360 \mathrm{~m} 3 / \mathrm{h}$, Motor power: $45 \mathrm{~kW}$ and Weight: $512 \mathrm{~kg}$ [7].

\subsection{Calculation of area heat exchange}

\subsubsection{Characteristics of water in secondary circuit}

$p_{1}=100 \mathrm{kPa}$ - water pressure in secondary circuit,

$t_{2}^{u l}=50^{\circ} \mathrm{C}$ - inlet water temperature in secondary circuit exchanger,

$t_{2}^{i z}=40^{\circ} \mathrm{C}$ - outlet water temperature in secondary circuit exchanger and

$\dot{m}_{t v}=66 l / s-$ mass flow of water.

\subsubsection{Water performance in primary circulit}

$p_{2}=3,5 \mathrm{bar}=350 \mathrm{kPa}$ - pressure water of primary circulit,

$t_{1}^{u l}=28^{\circ} \mathrm{C}$ - inlet temperature water in heat exchanger primary circulit and

$t_{1}^{i z}=35^{\circ} \mathrm{C}$ - outlet temperature water in heat exchanger primary circulit.

\subsubsection{Heat quantity which recive primary circulit water}

Heat quantity which give in secondary circulit water be calculated according to the following:

$$
Q_{d}=\dot{m}_{t v}\left(i_{2}^{u l}-i_{2}^{i z}\right)
$$

where are:

$i_{2}^{u l}=209,34 \mathrm{~kJ} / \mathrm{kg} \quad\left(t=50^{\circ} \mathrm{C}\right)$ - enthalpy secundary circulit water at outlet heat excanger,

$i_{2}^{i z}=167,53 \mathrm{~kJ} / \mathrm{kg} \quad\left(t=40^{\circ} \mathrm{C}\right)-$ enthalpy secondary circulit water at outlet heat excanger and

$$
Q_{d}=66(209,34-167,53)=2759,46 k W
$$

Heat quantity which recive primary circulit water be calculated according to the following:

$$
Q_{t v}=\eta \cdot Q_{d},
$$

where $\eta=0,985$ is coefficient of used heating.

$$
Q_{t v}=2759,46 \cdot 0,985=2718 \mathrm{~kW}
$$

\subsubsection{Calculation of area heat exchange}

Flow of technological wather through heat exchanger can be determined by: 


$$
\begin{aligned}
& \dot{m}_{t v}=\frac{Q_{t v}}{\left(i_{1}^{i z}-i_{1}^{u l}\right)}, \\
& \dot{m}_{t v}=\frac{2718}{(142,45-117,37)}=108 \mathrm{l} / \mathrm{s} .
\end{aligned}
$$

Area of heat exchange is given by:

$$
A_{t v}=\frac{Q_{t v} \cdot K}{\Delta T_{\log }},
$$

where $Q_{t v}$ is heat quantity which recive primary circulit water (tehnical water), $K=1 / R$ is coefficient of resistance of heat passage, $R=4,5 \frac{\mathrm{Wm}^{2}}{\mathrm{~K}}$ is resistance of heat passage and $\Delta T_{\log }$ is middle logarithmic temperature.

Middle logarithmic temperature be calculated according to the following:

$$
\begin{aligned}
& \Delta T_{\log }=\frac{\Delta T_{v}-\Delta T_{m}}{l_{n} \frac{\Delta T_{v}}{\Delta T_{m}}}, \\
& \Delta T_{\log }=\frac{\left(t_{2}^{u l}-t_{1}^{i z}\right)-\left(t_{2}^{i z}-t_{1}^{u l}\right)}{l_{n} \frac{t_{2}^{u l}-t_{1}^{i z}}{t_{2}^{i z}-t_{1}^{u l}}}, \\
& \Delta T_{\log }=\frac{(50-35)-(40-28)}{l_{n} \frac{50-35}{40-28}}=\frac{3}{l_{n} \frac{15}{12}}=13,44
\end{aligned}
$$

Area of heat exchange should be calculated according to the following (17):

$$
A_{t v}=\frac{2718 \cdot \frac{1}{4,5}}{13,44}=44,94 \mathrm{~m}^{2}
$$

The characteristics of the plate heat exchanger: Firm: Alfa Laval, Test pressure: 13 bar, Design pressure: 10 bar, Min. temperature: $0{ }^{\circ} \mathrm{C}$, Netweight: $941 \mathrm{~kg}$ and Operating weight: $1117 \mathrm{~kg}$ [8].

\section{Conclusion}

The selection of compressors for different applications is a crucial issue in the process industry. It is usually the most expensive piece of equipment and has dominant influence on cycle efficiency. In this paper is presented a system of preparation and distribution of compressed instrument air to the consumer in the system of internal pneumatic transport of fly ash under the electrofilter, flues and steam air heaters and calculation cooling compressors. System of compressed air for electrofilter is an integral part of a whole, the pneumatic transport of fly ash for the silo.

Compressed air is distributed by seamless steel galvanized pipelines. Distribution pipeline is oriented towards consumers, apropos to all valves on pneumatic drive which are located under electrofilter (EPS) of unit 1 and unit 2, and to the consumers in pump stations 1 and 2. In function of assigned pressure, complete pipeline is dimensioned, apropos diameters of certain sections are specified.

Compressed air is used for manipulation and control in pneumatic transport process as well as for manipulation of pneumatic valves which are within automatic control of pneumatic transport. Locations which are supplied with compressed air: pressure vessels for pneumatic fly ash transport, air transport pipeline, armatures of ash receiver (plate gate valves), ash transport pipelines and pneumatic valves in bager station. Consumers, apropos places which are needed to be supplied with compressed air, altogether there are 226 pieces. Function of these valves is in program control of fly ash transport process which is managed by PLC. Safe operation of installation, apropos maintaining pressure in installation within limitations of minimal and maximal permissible pressure is supplied with regulation system which is located in the compressor. Compressor is in mutual automatic operation with reservoir of instrumental air where pressure should be between 6,3- 7,5 bars. When pressure in reservoir drops under 7,5 bars, and reaches value of minimum 
permissible operation pressure $\mathrm{p}_{\min }=6,3$ bars, automatically one compressor activates until maximal wanted pressure is not reached.

Selection of compressor for compressed air under electrofilter: air consumption by consumer for transmition in block 1: $\mathrm{Q}_{1}=53 \mathrm{~m} / \mathrm{h}$, air consumption by consumer for transmition in block $2: \mathrm{Q}_{2}=53 \mathrm{~m} / \mathrm{h}$, air consumption by consumer for transmition in pump stations 1 and 2 like consumers on air preheaters and under channel of flue gases: $\mathrm{Q}_{3}=15 \mathrm{~m}^{3} / \mathrm{h}$ and total air consumption increased for $20 \%: \mathrm{Q}=1,2 \cdot\left(\mathrm{Q}_{1}+\mathrm{Q}_{2}+\mathrm{Q}_{3}\right)=1,2 \cdot 121=145,2 \mathrm{~m}^{3} / \mathrm{h}$.

On the basis of calculated consumption of 145,2 $\mathrm{m}^{3} / \mathrm{h}$ compressor of firm Atlas Copco is selected: Type: GA15 Capacity: $160 \mathrm{~m}^{3} / \mathrm{h}$, Operation pressure: 7,5 bara , Power of electromotor: $15 \mathrm{~kW}$, Noise level: $64 \mathrm{~dB}$, Dimensions 1400 x 1225 x 650. On the base of selected compressor and accrding to Atlas Copco recommendation absorption dryers type CD 44 ( 2 piece) are chosen. And on the base of experience in designing system of compressed air, instrumental air reservoir is selected, volume $\mathrm{V}=2 \mathrm{~m}^{3}$.

Compressors of compressed air are water cooled, while compressors of control air are air cooled. Water for cooling of compresed air and compressors is used in secondary circuit which is closed. A water tank will be used to supply additional water should any losses of water occur during circulation. Water from primary circuit is supplied from unit 1 and flows to bager station. Circulation pump, heat exchanger and pipeline were selected in accordance with calculation.

In this paper is explained calculation cooling compressors. Cooling of compressors is going to be done in two cycles. In first cycle technological water circulates by pumps of first cycle. In second cycle "demi" water will circulate and cooled compressors and coolers of compressed air and also will be drived by pumps. Possible water lost through cooling process will be refunded from additional water tank which is connect with supplying water pipe line for cooling. Selection of circulation pump in secondary circuit (the characteristics of the pump): Firm: WILO, Type: IL150/260-18,5/4, Flow range: $216 \mathrm{~m}^{3} / \mathrm{h}$, Motor power: 18,5 kW and Weight $309 \mathrm{~kg}$ and selection of circulation pump in primary circuit: Firm: WILO, Type: IL200/320-45/4, Flow range: $360 \mathrm{~m} 3 / \mathrm{h}$, Motor power: $45 \mathrm{~kW}$ and Weight: $512 \mathrm{~kg}$. The characteristics of the plate heat exchanger: Firm: Alfa Laval, Test pressure: 13 bar, Design pressure: 10 bar, Min. temperature: $0{ }^{\circ} \mathrm{C}$, Netweight: $941 \mathrm{~kg}$ and Operating weight: $1117 \mathrm{~kg}$. Optimized operation of the compressor is becoming increasingly important, especially for larger systems of compressed air depending on the industry. As the production rate in plants grow with plant development, the operating conditions of the compressor will change. It is therefore important that the compressed air supply system is based both on the current needs, and the needs in the future.

\section{References}

[1] Atlas Copco Airpower NV, (2015), Compressed Air Manual 8th edition, Belgium, ISBN 9789081535809

[2] Bloch, H. P., (2006), Compressors and Modern Process Applications, John Wiley \& Sons, Hoboken, New Jersey, ISBN 0-471-72792-X

[3] Bloch, H. P., (2006), A Practical Guide to Compressor Technology, 2nd Ed., John Wiley \& Sons, Hoboken, New Jersey, ISBN 0-471-727930-8

[4] Hadziahmetovic, H., Dzaferovic, E., Hodzic, N., (2012), System of compressed air for electrofilrer in thermal power plant, Annals of DAAAM for 2012 \& Proceedings of the 23rd International DAAAM Symposium, Volume 23, No.1, ISSN 2304-1382, ISBN 978-3-901509-91-9, Ed. B. Katalinic, Published by DAAAM International, Vienna, Austria

[5] Mills D., (2004), Pneumatic Conveying Design Guide, Second Edition, Butterworth-Heinemann, ISBN $0750654716, \mathrm{UK}$.

[6] Seshaiah, N.,(2006), Experimental and Computational Studies on Oil Injected Twin-Screw Compressor, Doctoral Thesis submitted to National Institute of Technology, Rourkela

[7] Wilo Product Catalog (2014), Pumps and systems for Building Services, Water Management, and Groundwater, Dortmund, Germany

[8] http://doc.texnikoi.gr/ylikadata/rtfs/laval4.pdf (2016), Alfa Laval plate heat exchangers, A product catalogue for comfort heating and cooling

[9] Hadziahmetovic, H. \& Dzaferovic, E., (2009), Ash pneumatic conveying from existing silos no. 4 to two new silos and ash loading in autocisterns - The 20th INTERNATIONAL DAAAM SYMPOSIUM "Intelligent Manufacturing \& Automation: Theory, Practice \& Education", 25-28th November 2009, Vienna, Austria

[10] Bogović, I-N., Barišić, B., Katalinić, B., Kršulja, M., Car, Z.,(2011), Digitizing system ATOS - measuring turbo compressor housing, Annals of DAAAM for 2011 \& PROCEEDINGS of the 22nd International DAAAM Symposium / Katalinić, Branko (ur.). - Vienna : DAAAM International Vienna , 2011. 1367-1368 (ISBN: 978-3901509-83-4)

[11] Bibire L., Ghenadi A., Topliceanu L., (2011), Maintenance -Reliability Duality For A 40 Bars Compressor From A Pet Bottling Line, The 22nd DAAAM World Symposium "Intelligent Manufacturing \& Automation: Power of Knowledge and Creativity", Vienna, 23-26th November 2011, ISBN 978-3-901509-83-4, ISSN 1726-9679, pag. 0029-0030 